\title{
Lung cancer cell invasion and expression of intercellular adhesion molecule-1 (ICAM-1) are attenuated by secretory phospholipase $\mathbf{A}_{2}$ inhibition
}

Jessica A. Yu, MD, Miral R. Sadaria, MD, Xianzhong Meng, MD, PhD, Sanchayita Mitra, MS, Lihua Ao, BS, David A. Fullerton, MD, and Michael J. Weyant, MD

\begin{abstract}
Objective: Invasive lung tumors are associated with intercellular adhesion molecule-1 (ICAM-1) expression. Secretory phospholipase $\mathrm{A}_{2}$ ( $\mathrm{sPLA}_{2}$ ) enzymes produce inflammatory mediators that stimulate ICAM- 1 expression, and upregulation of $\mathrm{PLA}_{2}$ activity can enhance metastasis. We hypothesize a link between SPLA $\mathrm{A}_{2}$ activity, ICAM-1 expression, and tumor cell invasion. We propose that inhibition of SPLA $_{2}$ modulates ICAM-1 expression in cancer cells and attenuates their invasiveness.
\end{abstract}

Methods: Human lung adenocarcinoma cells (A549) were treated with an ICAM-1 blocking antibody and assayed for invasion. Lung cancer cells (A549 and H358) were then treated with an $\mathrm{SPLA}_{2}$ inhibitor and evaluated by immunoblotting for ICAM-1 expression. Next cells (A549) treated with $\mathrm{SPLA}_{2}$ inhibitor were assayed for invasion. Finally, $\mathrm{SPLA}_{2}$ messenger RNA and protein expression were evaluated by quantitative reversetranscriptase polymerase chain reaction and immunofluorescence microscopy, respectively. Statistical analysis was performed by the Student $t$ test or analysis of variance, as appropriate.

Results: Antibody blockade of ICAM-1 decreased lung cancer cell invasion. sPLA 2 inhibition significantly reduced ICAM-1 expression and invasion. $\mathrm{sPLA}_{2}$ inhibition also significantly decreased $\mathrm{SPLA}_{2}$ mRNA expression and immunofluorescent staining of $\mathrm{SLA}_{2}$.

Conclusions: $\mathrm{sPLA}_{2}$ plays a significant role in mediating the inflammatory signals that induce ICAM- 1 expression in lung cancer cells. Inhibition of the enzyme can significantly decrease ICAM-1 expression and subsequent cancer cell invasion. This lays the groundwork for further investigation into the cellular mechanisms of sPLA 2 and its role in lung cancer. (J Thorac Cardiovasc Surg 2012;143:405-11)

Approximately $75 \%$ of patients with lung cancer have metastatic disease at the time of diagnosis, and mortality largely results from the burden of metastatic spread. ${ }^{1}$ Improving therapy for patients with invasive disease could dramatically affect lung cancer mortality and morbidity.

Metastatic cancer cells undergo a structural alteration to invade neighboring tissue. Invasion can be facilitated by expression of adhesion molecules such as intercellular adhesion molecule-1 (ICAM-1). ${ }^{2}$ ICAM-1 is a member of the immunoglobulin supergene family of adhesion molecules and its expression is essential for the transendothelial migration of white blood cells from capillary beds into tissues.

\footnotetext{
From the Section of General Thoracic Surgery, Division of Cardiothoracic Surgery, University of Colorado School of Medicine, Aurora, Colo.

Disclosures: Authors have nothing to disclose with regard to commercial support. Read at the 37th Annual Meeting of The Western Thoracic Surgical Association, Colorado Springs, Colorado, June 22-25, 2011.

Received for publication June 21, 2011; revisions received Sept 28, 2011; accepted for publication Oct 20, 2011.

Address for reprints: Michael J. Weyant, MD, Associate Professor of Surgery, University of Colorado School of Medicine, 12631 E 17th Ave, C310, Aurora, CO 80045 (E-mail: Michael.Weyant@ucdenver.edu). 0022-5223/\$36.00

Copyright (C) 2012 Published by Elsevier Inc. on behalf of The American Association for Thoracic Surgery

doi:10.1016/j.jtcvs.2011.10.026
}

In malignant disease, ICAM-1 expression has been associated with more aggressive lesions in melanoma, gastric, breast, lung, and other epithelial-derived cancers. ${ }^{2,3}$ Serum ICAM-1 levels are increased in patients with nonsmall cell lung cancer, ${ }^{4}$ and elevated serum levels have been correlated with advanced cancer stage. ${ }^{5-7}$ Histologically, levels of ICAM-1 expression in lung cancer tissue are proportional to tumor stage and associated with metastatic spread to lymph nodes. ${ }^{7,8}$ Laboratory models have demonstrated that ICAM-1 upregulation can promote cancer cell invasion. Furthermore, decreased tumor cell invasion is associated with decreased levels of ICAM-1 expression. ${ }^{7,9}$

Secretory phospholipase $\mathrm{A}_{2}\left(\mathrm{sPLA}_{2}\right)$ enzymes produce inflammatory mediators that stimulate ICAM- 1 expression. These enzymes catalyze the release of arachidonic acid from cell membranes leading to the production of eicosanoids such as prostaglandins, thromboxanes, and leukotrienes. ${ }^{10,11}$ Recently a number of studies have looked beyond the role of phospholipase enzymes in inflammation to probe their contribution to the pathogenesis of cancer. ${ }^{12-17}$ Stimulation of phospholipase $\mathrm{A}_{2}\left(\mathrm{PLA}_{2}\right)$ activity enhances the metastatic potential of lung cancer cells in vivo. ${ }^{13}$ Interestingly, PLA $_{2}$ activity in tumor-associated macrophages also correlates with a more 


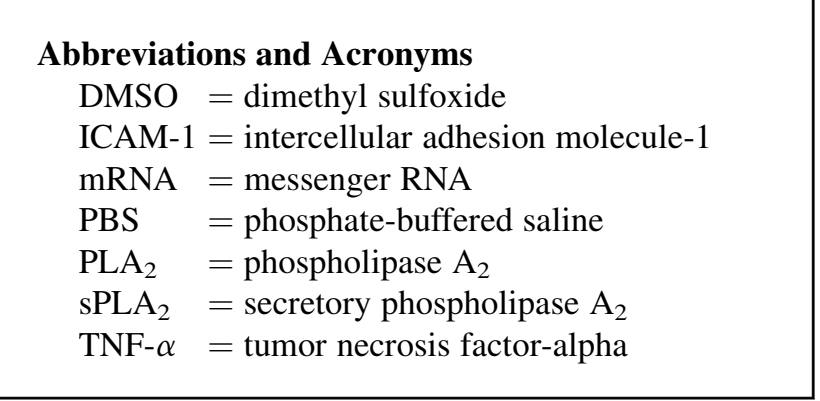

invasive phenotype in vivo. ${ }^{12}$ Regarding SLA $_{2}$ specifically, pharmacologic inhibition of the enzyme in lung cancer cells increases apoptosis and attenuates proliferation. ${ }^{17}$ Inhibition of sPLA $\mathrm{P}_{2}$ has also been shown to attenuate total cellular and soluble ICAM-1 expression in esophageal cancer cells. ${ }^{16}$ We hypothesize a link between sPLA $_{2}$ and ICAM-1 in lung cancer cells. We propose that $\mathrm{SLA}_{2}$ mediates ICAM1 expression in lung cancer cells and that inhibition of $\mathrm{sPLA}_{2}$ decreases the invasive potential of lung cancer cells.

\section{MATERIALS AND METHODS Cell Culture and Reagents}

Two human non-small cell lung cancer cell lines were used. A549 cells were donated by Dr Banerjee (University of Colorado, Aurora, Colo). NCIH358 cells were a gift from Dr O'Neill (Brigham Young University, Provo, Utah). Cells were maintained at $37^{\circ} \mathrm{C}$ in $5 \%$ carbon dioxide in Ham's F-12 (A549) or RMPI (H358) containing 10\% fetal bovine serum. Stock and experimental solutions of tumor necrosis factor-alpha (TNF- $\alpha$ ) (Sigma Aldrich, St Louis, Mo) were prepared in phosphate-buffered saline (PBS). The group IIa sPLA 2 inhibitor S3319 (Sigma Aldrich) was dissolved in dimethyl sulfoxide (DMSO). DMSO served as a vehicle control for all experiments with a maximum experimental concentration of $0.08 \%$. DMSO was used for the same time points as the inhibitor. Rabbit anti-ICAM-1 (Santa Cruz Biotechnology, Inc, Santa Cruz, Calif) and anti-glyceraldehyde-3phosphate antibodies (Cell Signaling Technology, Inc, Danvers, Mass) were used for Western blot. Sheep anti-ICAM-1 and a polyclonal sheep immunoglobulin G control (R\&D Systems, Minneapolis, Minn) were used for ICAM-1 blockade experiments.

\section{Matrigel Invasion Assay}

A modified Boyden chamber assay was created using Transwell 8- $\mu \mathrm{m}$ permeable inserts (Corning, Corning, NY) coated with $20-\mu \mathrm{g} / 100 \mu \mathrm{L}$ Matrigel matrix (BD Biosciences, Franklin Lakes, NJ) placed in 24-well cell culture plates. For the neutralizing antibody experiment, A549 cells were plated in full media (media with $10 \%$ fetal bovine serum) for 24 hours and then serum-starved (media with $0.5 \%$ fetal bovine serum) for 24 hours before adding TNF- $\alpha$ for 8 hours. Cells were trypsinized, counted, and resuspended in serum-starved media containing ICAM-1 neutralizing antibody $(25 \mu \mathrm{g} / \mathrm{mL})$ in a rotating incubator for 1 hour at $37^{\circ} \mathrm{C}$. An aliquot of cells incubated with sheep immunoglobulin $\mathrm{G}$ at the same concentration served as an antibody control. Then, $5 \times 10^{4}$ cells were placed on each insert and allowed to migrate for 36 hours using full media with $10 \%$ fetal bovine serum as a chemoattractant in the bottom chamber. Inserts were fixed and stained with $0.4 \%$ crystal violet, $0.2-\mathrm{mol} / \mathrm{L}$ citrate for 1 hour, washed twice with PBS, then once with deionized water. Cells on the upper side of the insert were removed with a cotton swab. Remaining cells in the center of the insert were counted using a stereo microscope (Leica, Wetzlar,

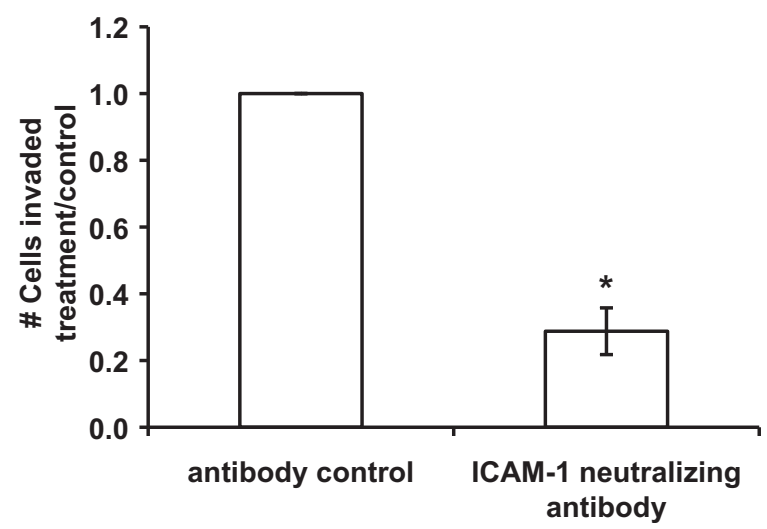

FIGURE 1. Intercellular adhesion molecule-1 (ICAM-1) determines invasiveness of lung adenocarcinoma cells. Statistically significant reduction in invasion of A549 cells pretreated with a neutralizing ICAM-1 antibody. $* P=.003$ compared with antibody control, $\mathrm{n}=9$.

Germany) and SPOT basic imaging software (SPOT Imaging Solutions, Sterling Hills, Mich).

For the $\mathrm{SPLA}_{2}$ inhibitor invasion assay, A549 cells were first grown in 25 -mL flasks at a concentration of $7 \times 10^{6}$ cells $/ \mathrm{mL}$ for 24 hours and then serum-starved for 24 hours. Control cells were incubated with DMSO in serum-starved media, and then TNF- $\alpha$ was added to the media for 8 hours. Treatment cells were incubated with $20-\mu \mathrm{mol} / \mathrm{L}$ sPLA 2 inhibitor in serum-starved media for 1 hour, and then $20-\mathrm{ng} / \mathrm{mLTNF}-\alpha$ was added to the treatment media for 8 hours. After cells were counted and resuspended in serum-starved media, $5 \times 10^{4}$ cells were placed on each insert and allowed to migrate for 36 hours. Cells were stained and counted as described.

\section{Western Blot Analysis}

For analysis, $3 \times 10^{6}$ cells were plated in 6-well culture plates in full media for 24 hours and then serum-starved for 24 hours before treatment. Cells were incubated with incrementally increasing concentrations of the $\mathrm{SPLA}_{2}$ inhibitor in serum-starved media for 1 hour; then $20-\mathrm{ng} / \mathrm{mL}$ TNF- $\alpha$ was added to the treatment media for 8 hours. Control cells were incubated with DMSO in serum-starved media and stimulated with TNF$\alpha$ for 8 hours. Cells were lysed with Laemelli buffer and proteins resolved using sodium dodecyl sulfate-polyacrylamide gel electrophoresis. The proteins were transferred to nitrocellulose membranes and probed for ICAM-1 and glyceraldehyde-3-phosphate. Blocking solution contained $0.5 \%$ nonfat milk in $1 \times$ PBS with $0.1 \%$ Tween- 20 . Antibodies were diluted in $5 \%$ bovine serum albumin and $1 \times$ PBS with $0.1 \%$ Tween- 20 . After incubation with horse radish peroxidase-conjugated secondary antibody, bound antibody was detected using enhanced chemiluminescence (Pierce Protein Research Products; Thermo Scientific, Rockford, Ill). Image J software (National Institutes of Health, Bethseda, Md) was used for densitometric analysis of the protein band of interest.

\section{Lactic Dehydrogenase Cytotoxicity Assay}

Cells, 5000 per well, were plated in a 96-well culture plate and treated as described for Western blot analysis of ICAM-1 expression. Cell supernatants were assayed for lactic dehydrogenase activity per manufacturer instructions (Cayman Chemicals, Ann Arbor, Mich).

\section{Immunofluorescence Microscopy}

Cells, 5000 per chamber, were cultured on Lab-Tek II 8-well glass chamber slides (Thermo Scientific, Rochester, NY) in full media for 24 hours and then serum-starved for 24 hours. Cells were pretreated with incrementally 

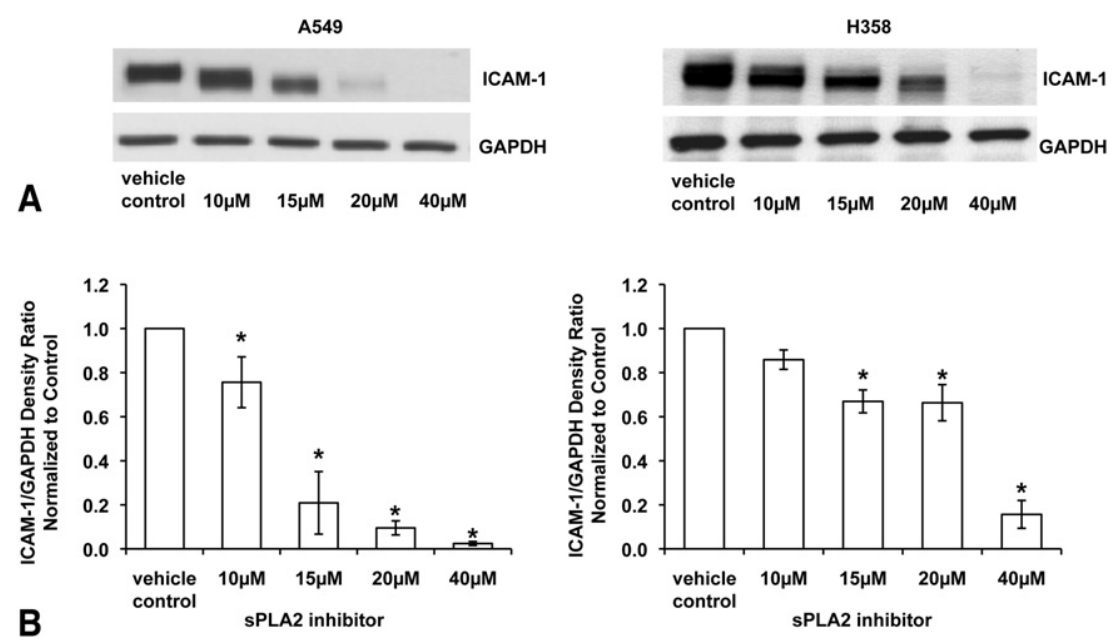

FIGURE 2. Decreased total cellular expression of intercellular adhesion molecule-1 (ICAM-1) in lung adenocarcinoma cells treated with secretory phospholipase $\mathrm{A}_{2}\left(s \mathrm{PLA}_{2}\right)$ inhibitor. Representative Western blot of A549 cells and H358 cells shows a concentration-dependent decrease in ICAM-1 expression (A). Densitometric analysis of ICAM-1 protein bands normalized to vehicle control. A statistically significant decrease in ICAM-1 expression was seen in both cell lines (B). ${ }^{*} P<.001$ compared with control, $\mathrm{n}=4$ for each experiment. GAPDH, Glyceraldehyde-3-phosphate.

increasing concentrations of the $\mathrm{SLA}_{2}$ inhibitor in serum-starved media for 1 hour and then stimulated with $20-\mathrm{ng} / \mathrm{mL}$ TNF- $\alpha$ for 8 hours. Control cells were incubated with DMSO in serum-starved media and stimulated with TNF- $\alpha$ for 8 hours. Immunofluorescence microscopy was performed to evaluate $\mathrm{SPLA}_{2}$ expression in A549 cells as previously described. ${ }^{15}$

\section{Reverse-Transcriptase Polymerase Chain Reaction}

Cells were grown in 12-well culture plates at a density of $1 \times 10^{5}$ cells per well with full media and then serum-starved media for 24 hours each. Cells were incubated with $20-\mu \mathrm{mol} / \mathrm{L} \mathrm{sPLA}_{2}$ inhibitor for 1 hour before TNF- $\alpha$ was added for 2 hours, 1 hour, and 30 minutes before messenger RNA collection. Control cells were incubated with DMSO in serum-starved media and stimulated with $20-\mathrm{ng} / \mathrm{mL}$ TNF- $\alpha$ for the same time points. A549 cells were analyzed for mRNA expression of $\mathrm{SPLA}_{2}$ using quantitative reverse-transcriptase polymerase chain reaction as previously described. ${ }^{15}$ Messenger RNA for $\mathrm{SPLA}_{2}$ was normalized to mRNA for glyceraldehyde-3-phosphate in the same sample.

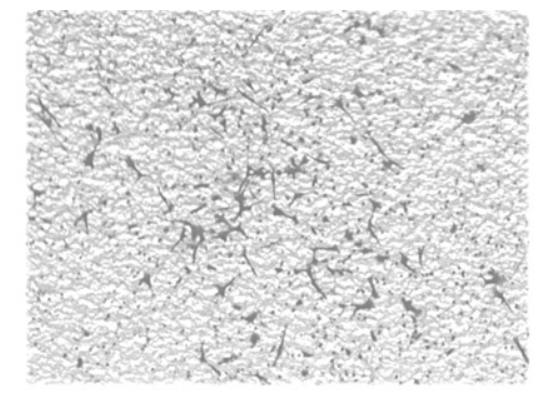

A

vehicle control

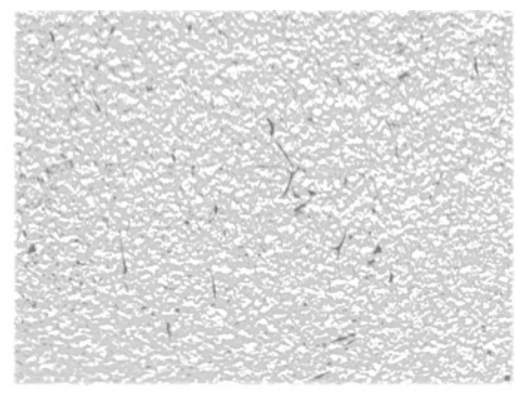

$20 \mu \mathrm{M}$ sPLA2 inhibitor

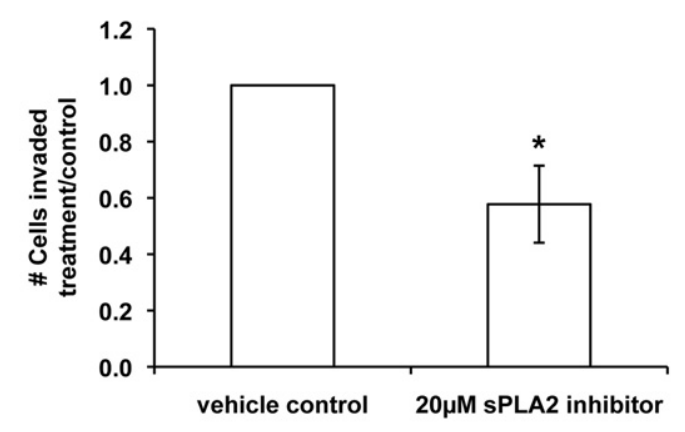

B

FIGURE 3. Secretory phospholipase $\mathrm{A}_{2}\left(s P L A_{2}\right)$ inhibition of lung adenocarcinoma cells decreases invasion through a modified basement membrane matrix. Representative image of cells that have migrated through the matrix (A). Statistically significant reduction in invasion of A549 cells treated with $20-\mu \mathrm{mol} / \mathrm{L}$ sPLA 2 inhibitor for 8 hours (B). $* P=.019$ compared with control, $\mathrm{n}=17$. 

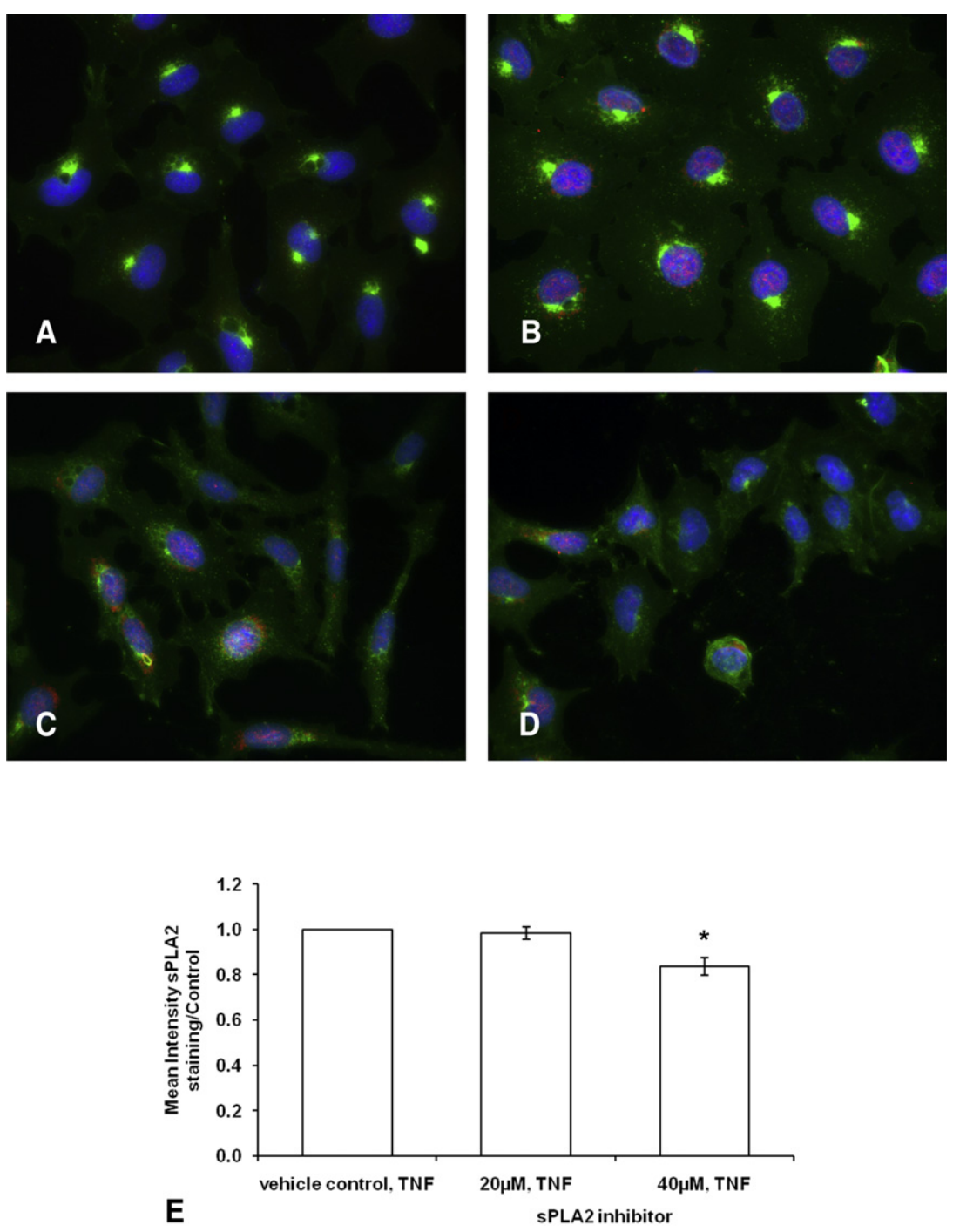

FIGURE 4. Representative immunofluorescent images of group IIa secretory phospholipase $\mathrm{A}_{2}\left(s P L A_{2}\right)$ expression in A549 cells. Cell membranes appear green, nuclei appear blue, and $\mathrm{SPLA}_{2}$ appears red. The negative control was cells in vehicle control media and tumor necrosis factor-alpha $(T N F-\alpha)$ for 8 hours stained with non-immune matched immunoglobulin G (A). In the subsequent images, cells were stained with group IIa sPLA antibody, vehicle control, and TNF- $\alpha$ for 8 hours (B), TNF- $\alpha$ for 8 hours in the presence of $20-\mu$ mol/L sPLA 2 inhibitor (C), and TNF- $\alpha$ for 8 hours in the presence of $40-\mu \mathrm{mol} / \mathrm{L}$ sPLA 2 inhibitor (D). The decrease in $\mathrm{sPLA}_{2}$ staining was significant at $40-\mu \mathrm{mol} / \mathrm{L}$ sPLA 2 inhibitor compared with control (E). $* P=.023$.

\section{Statistical Analysis}

All data distributions were inspected before statistical analysis. The Student $t$ test was performed for 2 group comparisons, and an analysis of variance test was performed when comparing 3 or more groups. No multiple comparisons were conducted. SAS version 9.2 (SAS Institute, Inc, Cary, $\mathrm{NC}$ ) was used for all statistical analysis.

\section{RESULTS}

ICAM-1 Blockade Decreases Invasion of A549 Cells

Cells treated with a neutralizing ICAM-1 antibody demonstrated significantly decreased invasion, over $70 \%$ compared with an antibody control (Figure 1, $P=.003)$.

\section{SPLA 2 Inhibition Reduces ICAM-1 Expression and Attenuates Invasion}

Treatment of A549 and H358 cells with a specific group IIa $\mathrm{SPLA}_{2}$ inhibitor led to a concentration-dependent decrease in ICAM-1 expression in both cell lines with a greater than $80 \%$ decrease at the maximum concentration of $40 \mu \mathrm{mol} / \mathrm{L}$ (Figure 2, $A$ and $B, P<.001$, at 15 , 20 , and $40 \mu \mathrm{mol} / \mathrm{L}$ in both cell lines). The concentrations used did not cause cell lysis as evaluated by a lactic dehydrogenase cytotoxicity assay (data not shown). Invasion of A549 cells through a modified basement membrane matrix was significantly decreased in the presence of 


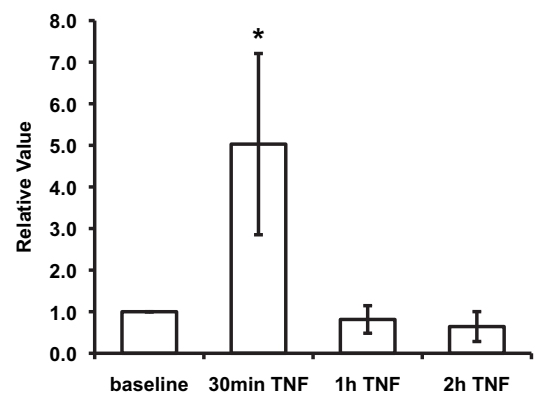

A

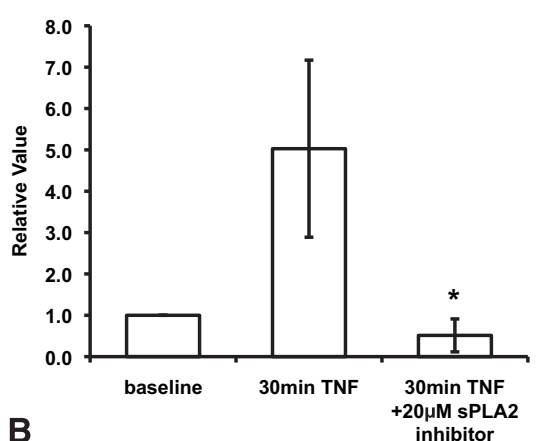

B

inhibitor

FIGURE 5. Group IIa secretory phospholipase $\mathrm{A}_{2}\left(s P L A_{2}\right)$ inhibition decreases group IIa sPLA 2 production in non-small cell lung cancer cells. Tumor necrosis factor-alpha $(T N F-\alpha)$ for 30 minutes increases production of $\mathrm{sPLA}_{2}$ mRNA (A); $* P=.022$, $\mathrm{n}=3$ run in triplicate. A $20-\mu$ mol/L dose of $\mathrm{sPLA}_{2}$ inhibitor decreases $\mathrm{sPLA}_{2}$ mRNA expression $(\mathrm{B}) ;{ }^{*} P=.044, \mathrm{n}=3$ run in triplicate.

20- $\mu \mathrm{mol} / \mathrm{L}$ group IIa sPLA 2 inhibitor (Figure 3, $A$ and $B$, $P=.019)$.

\section{SPLA $_{2}$ Inhibition Decreases $\mathbf{S P L A}_{2}$ Expression in A549 Cells}

Cells treated with $\mathrm{SPLA}_{2}$ inhibitor show a decrease in sPLA $_{2}$ staining by immunofluorescence (Figure 4, $P=.023)$. Quantitative reverse-transcriptase polymerase chain reaction shows a significant increase in group IIa $\mathrm{sPLA}_{2}$ mRNA with TNF- $\alpha$ stimulation for 30 minutes (Figure $5, A, P=.022$ ) and a decrease in group IIa $\mathrm{SPLA}_{2}$ mRNA in the presence of $20 \mu \mathrm{mol} / \mathrm{L}$ of inhibitor (Figure 5, $B, P=.044$ ).

\section{DISCUSSION}

Although previous investigations have linked $\mathrm{PLA}_{2}$ activity to ICAM-1 expression, this is the first study to demonstrate that pharmacologic inhibition of group IIa $\mathrm{sPLA}_{2}$ decreases ICAM-1 expression and invasion in lung cancer cells. ${ }^{15,18}$

This effect of $\mathrm{sPLA}_{2}$ inhibition is especially noteworthy inasmuch as the decrease in ICAM-1 expression is seen in 2 different cell lines that both harbor K-ras mutations but differ in functional p53 (wild type in A549, mutant in H358) and liver kinase B1 (mutant in A549 and wild type in H358) status. Tumor protein 53 is a widely studied tumor suppressor and liver kinase B1 is an inhibitor of mammalian target of rapamycin. Unimpeded activity of mammalian target of rapamycin can be promalignant, and mammalian target of rapamycin is often aberrantly activated in lung cancers with oncogenic K-ras mutations. ${ }^{19}$

The role of adhesion molecules in the pathogenesis, diagnosis, and prognosis of cancer has been hotly investigated. In lung cancer, ICAM-1 and E-cadherin are recognized as serum markers and, at the cellular level, as role players in metastatic transformation. ${ }^{2,4}$ ICAM- 1 is inducible by cytokines within the inflammatory milieu of the tumor microenvironment. Its potential role in invasion is implicated by increased in vitro and in vivo invasion with ICAM-1 overexpression. $^{7}$ Our experimental approach demonstrates that by targeting ICAM-1 through a small molecule inhibitor to $\mathrm{sLA}_{2}$, as well as a neutralizing antibody against cell surface ICAM-1, invasion was decreased.

Antibody blockade of ICAM-1 resulted in a greater inhibition of invasion than the $\mathrm{SPLA}_{2}$ inhibitor, suggesting a therapeutic application for an ICAM-1 antibody. Antibody therapy targeting adhesion molecules is not ideal because adhesion proteins are essential for normal leukocyte function and the risk may outweigh the benefit. Solid tumors are particularly challenging targets for antibody therapy secondary to poor tumor penetration compared with small molecules. ${ }^{20}$ Despite decades of research, the Food and Drug Administration has not yet approved any monoclonal antibody available for lung cancer. Importantly, small molecule inhibitors like the $\mathrm{SPLA}_{2}$ inhibitor can achieve the same goal of reducing ICAM-1 expression, in addition to exhibiting other antitumor effects, for less immune reactivity and expense.

$\mathrm{PLA}_{2}$ enzymes produce arachidonic acid, a precursor to products of cyclooxygenase enzymes such as prostaglandins. Prostaglandins have been implicated in the pathogenesis of epithelial-derived tumors and prostaglandin production is elevated in tumor specimens of patients with lung cancer. ${ }^{21}$ In vivo studies of cyclooxygenase-2 inhibitors have shown therapeutic trends. A clinical trial of celecoxib in non-small cell lung cancer is associated with decreased biomarkers associated with metastatic potential. ${ }^{22}$ In addition to its enzymatic activity, $\mathrm{SPLA}_{2}$ also functions as a ligand with the ability to interact with cell surface receptors like CD40, of the TNF- $\alpha$ receptor family, to enhance monocyte response to inflammatory states and possibly potentiate $\mathrm{PLA}_{2}$ pathways. ${ }^{11}$ In this way, sPLA $_{2}$ secreted by cancer cells or tumor-associated cells may act as a ligand to further potentiate inflammatory cell signals associated with ICAM-1 expression. ${ }^{23}$ Effective $\mathrm{SPLA}_{2}$ inhibition may have an added advantage over cyclooxygenase-2 inhibitors by decreasing this potentiation. 
A striking result of this study is the finding that cellular inhibition of group IIa sPLA 2 in lung cancer cells decreases the production of the enzyme itself. Potential mechanisms could be through decreased transcriptional regulation either by the enzyme itself or through downstream products. In addition, lung cancer cell apoptosis increases with prolonged exposure to $\mathrm{sPLA}_{2}$ inhibition. ${ }^{17}$ The combination of decreased invasion and cancer cell viability from $\mathrm{SPLA}_{2}$ inhibition favors its potential as a therapeutic agent. As specific group IIa sPLA 2 inhibitors have already been studied in clinical trials for rheumatoid arthritis and sepsis, their potential application in malignancy is particularly appealing. ${ }^{24,25}$

The mechanism of SPLA $_{2}$ inhibition on ICAM-1 expression is likely dependent on the transcription factor nuclear factor- $\kappa$ B. ${ }^{9,10,16}$ Elucidation of intracellular pathways affected by group IIa SPLA $_{2}$ inhibition in lung cancer cells is the topic of ongoing research.

In summary, these data suggest that $\mathrm{sLA}_{2}$ plays a significant role in mediating the inflammatory signals that induce ICAM-1 expression in lung cancer cells. In addition, this study demonstrates that pharmacologic inhibition of the enzyme can significantly decrease ICAM-1 expression and subsequent cancer cell invasion. This lays the groundwork for further investigation into the cellular mechanisms of $\mathrm{sPLA}_{2}$ and the effect of $\mathrm{sPLA}_{2}$ on lung cancer proliferation in vitro and in vivo.

\section{References}

1. Surveillance Epidemiology and End Results, Cancer Statistics Review. Bethesda: National Cancer Institute; 2010.

2. Makrilia N, Kollias A, Manolopoulos L, Syrigos K. Cell adhesion molecules: role and clinical significance in cancer. Cancer Invest. 2009;27:1023-37.

3. Roland CL, Harken AH, Sarr MG, Barnett CC. ICAM-1 expression determines malignant potential of cancer. Surgery. 2007;141:705-7.

4. Gogali A, Charalabopoulos K, Zampira I, Konstantinidis AK, Tachmazoglou F, Daskalopoulos G, et al. Soluble adhesion molecules E-cadherin, intercellular adhesion molecule-1, and E-selectin as lung cancer biomarkers. Chest. 2010;138: 1173-9.

5. Grothey A, Heistermann P, Philippou S, Voigtmann R. Serum levels of soluble intercellular adhesion molecule-1 (ICAM-1, CD54) in patients with non-smallcell lung cancer: correlation with histological expression of ICAM-1 and tumour stage. Br J Cancer. 1998;77:801-7.

6. Kamiyoshihara M, Kawashima O, Otani Y, Morishita Y. Clinical significance of the preoperative serum-soluble intercellular adhesion molecule-1 in non-small cell lung cancer. J Cardiovasc Surg (Torino). 2002;43:729-34.

7. Lin YC, Shun CT, Wu MS, Chen CC. A novel anticancer effect of thalidomide: inhibition of intercellular adhesion molecule-1-mediated cell invasion and metastasis through suppression of nuclear factor-kB. Clin Cancer Res. 2006;12: 7165-73.

8. Passlick B, Pantel K, Kuboschok B, Angstwurm M, Neher A, Thetter O, et al. Expression of MHC molecules and ICAM-1 on non-small cell lung carcinomas: association with early lymphatic spread of tumour cells. Eur J Cancer. 1996; 32A:141-5.

9. Chen LM, Kuo CH, Lai TY, Lin YM, Su CC, Hsu HH, et al. RANKL increases migration of human lung cancer cells through intercellular adhesion molecule-1 up-regulation. J Cell Biochem. 2011;112:933-41.

10. Thommesen L, Sjursen W, Gasvik K, Hanssen W, Brekke OL, Skattebol L, et al. Selective inhibitors of cytosolic or secretory phospholipase A2 block TNFinduced activation of transcription factor nuclear factor-kappaB and expression of ICAM-1. J Immunol. 1998;161:3421-30.
11. Fuentes L, Hernández M, Fernández-Avilés FJ, Crespo MS, Nieto ML. Cooperation between secretory phospholipase A2 and TNF-receptor superfamily signaling. Circ Res. 2002;91:681-8.

12. Weiser-Evans MCM, Wang XQ, Amin J, Putten VV, Choudhary R, Winn RA, et al. Depletion of cytosolic phospholipase A2 in bone marrow-derived macrophages protects against lung cancer progression and metastasis. Cancer Res. 2009;69:1733-8.

13. Ho JN, Lee SB, Lee SS, Yoon SH, Kang GY, Hwang SG, et al. Phospholipase A2 activity of peroxiredoxin 6 promotes invasion and metastasis of lung cancer cells. Mol Cancer Ther. 2010;9:825-32.

14. Babu A, Meng X, Banerjee AM, Gamboni-Robertson F, Cleveland JC, Damle S, et al. Secretory phospholipase $\mathrm{A}_{2}$ is required to produce histologic changes associated with gastroduodenal reflux in a murine model. J Thorac Cardiovasc Surg. 2008;135:1220-7.

15. Mauchley D, Meng X, Johnson T, Fullerton DA, Weyant M. Modulation of growth in human esophageal adenocarcinoma cells by group IIa secretory phospholipase A A $_{\text {. }}$ Thorac Cardiovasc Surg. 2010;139:591-9.

16. Sadaria M, Meng X, Fullerton DA, Reece TB, Shah RR, Grover FL, et al. Secretory phospholipase $\mathrm{A}_{2}$ inhibition attenuates intercellular adhesion molecule-1 expression in human esophageal adenocarcinoma cells. Ann Thorac Surg. 2011;91: 1539-45.

17. Yu JA, Sadaria MR, Meng X, Fullerton DA, Weyant MJ. Secretory phospholipase A2 inhibition promotes apoptosis in lung cancer cells and modulates ERK 1/2 activation. J Thorac Oncol. 2011;6:S660.

18. Yokote K, Morisaki N, Zenibayashi M, Ueda S, Kanzaki T, Saito Y, et al. The phospholipase-A2 reaction leads to increased monocyte adhesion of endothelial cells via the expression of adhesion molecules. Eur J Biochem. 1993;217:723-9.

19. Van Veelan W, Korsse SE, van de Laar L, Peppelenbosch MP. The long and winding road to rational treatment of cancer associated with LKB1/AMPK/TSC/ mTORC1 signaling. Oncogene. 2011;30:2289-303.

20. Ricart AD. Immunoconjugates against solid tumors: mind the gap. Clin Pharmacol Ther. 2011;89:512-23.

21. McLemore TL, Hubbard WC, Litterst CL, Liu MC, Miller S, McMahon NA, et al. Profiles of prostaglandin biosynthesis in normal lung and tumor tissue from lung cancer patients. Cancer Res. 1988;48:3140-7.

22. Reckamp KL, Gardner BK, Figlin RA, Elashoff D, Krysan K, Dohadwala M, et al. Tumor response to combination celecoxib and erlotinib therapy in non-small cell lung cancer is associated with a low baseline matrix metalloproteinase-9 and a decline in serum-soluble E-cadherin. $J$ Thorac Oncol. 2008;3:116-24.

23. Wu Y, Zhou BP. TNF- $\alpha / \mathrm{NF}-\kappa \mathrm{B} /$ Snail pathway in cancer cell migration and invasion. Br J Cancer. 2010;102:639-44.

24. Zeiher BG, Steingrub J, Laterre PF, Dmitrienko A, Fukijishi Y, Abraham E. EZZI Study Group. LY31590NA/S-5920, a selective inhibitor of group IIA secretory phospholipase A2, fails to improve clinical outcome for patients with severe sepsis. Crit Care Med. 2005;33:1741-8.

25. Bradley JD, Dmitrienko AA, Kivitz AJ, Gluck OS, Weaver AL, Wisenhutter C, et al. A randomized, double-blinded, placebo-controlled clinical trial of LY333013, a selective inhibitor of group II secretory phospholipase A2, in the treatment of rheumatoid arthritis. J Rheumatol. 2005;32:417-23.

\section{Discussion}

Dr Michael Mulligan (Seattle, Wash). Congratulations on your paper and a very nice presentation. I always appreciate seeing a lot of effort put into work, and clearly you did that. I noticed the article that your group put out via e-publication last month evaluating ICAM regulation with $\mathrm{sPLA}_{2}$ in esophageal cancer cells, and this is a nice extension of that work. It is always difficult to know what the next great research question is and you seem to be onto something here.

I have 3 questions, which I will ask one at the time.

The matrigel assay is used to screen cell lines and measure invasiveness, but ultimately it is a dead matrix and is devoid of either known or candidate ligands for ICAM-1. If you do a quick search, you can find that there is now a body of researchers who are looking at ICAM-1 not so much as an adhesion receptor, particularly in the invasion paradigm, but as a signaling molecule. That is a little 
bit different. Indeed, your findings suggest that your greatest effects on invasiveness were with direct inhibition of ICAM-1 and not with sPLA $\mathrm{A}_{2}$ inhibition indirectly, thereby affecting expression of ICAM-1. Can you postulate how ICAM-1 is regulating invasiveness? Is it merely adjusting the phenotype or something more invasive, or how does blockade of ICAM-1 allow you to digest through a collagen matrix differently than without?

Dr Yu. ICAM-1 can be considered a phenotype of invasive cells. How it helps the tumor cells invade through the matrix or, more important, in an in vivo model promote metastatic disease, is not well defined. There are other mediators of invasion that we did not necessarily address here, such as metalloproteinases that help digest the matrix. ICAM-1 is a reasonable marker of invasion given all of the evidence in serum and in tumor tissue. There are always limitations to in vitro studies, and I think the next move is to try $\mathrm{SPLA}_{2}$ inhibition in an in vivo model.

Dr Mulligan. It is exciting because with direct blockade you definitely showed an effect; yet there is no ICAM ligand in the assay, so it has to be signaling somehow. There is a lot of potential there for another award.

The second question relates to specificity and loss of specificity with S3319, also known as KHO64. If you look at the dose ranges or the therapeutic concentrations for most of the small molecule targeted interventions that we use, like Tarceva (Hoffmann-La Roche, Basel, Switzerland) or any other "nibs," they are always in the low nanomolar range, yet you were using up to $40 \mu \mathrm{mol} / \mathrm{L}$. What data do you have to assess for loss of specificity or potential off-target effects?

Dr Yu. It is difficult to correlate concentrations that are used in vitro with an eventual in vivo concentration. One thing we did do was look at the cytotoxicity of the small molecule inhibitor in the lung cancer cells using a lactic dehydrogenase cytotoxicity assay. All the concentrations and time points we used were viable for the cells.
Dr Mulligan. However, you are seeing something weird, too, in that you are seeing an enzyme inhibitor having a sort of an autocrine reverse effect on transcription of the enzyme itself. It could be that you have disrupted all sorts of transcriptional mechanisms that you just have not tracked yet, so it would be good to go back and look at that.

The last question is a more global one. Activation of $\mathrm{SPLA}_{2}$ is a fairly upstream activation event, particularly if you try to relate it to ICAM-1 activation. There are a lot of intervening steps., including activation of cyclooxygenase. For the past 20 years there has been a lot of work looking at inhibition of those intermediate steps that should theoretically work reasonably well, but they do not work. I found about 100 publications or more this morning that demonstrated efficacy in cell systems and more than 50 clinical trials that showed that nothing worked when they tried to take it forward. What makes this different? Why should this work and is it safe? Because it is such an omnipresent enzyme that has so many functions, if we knock it out, what are we going to do to the wild type or to the patient?

Dr Yu. sPLA 2 is upstream. One of the interesting things about this particular enzyme is that it generates arachidonic acid, but it also has some other effects. For example, $\mathrm{sPLA}_{2}$ can function as a ligand and not just as an intracellular enzyme. These other functions may be targeted with inhibition of $\mathrm{SPLA}_{2}$. In terms of $\mathrm{SPLA}_{2}$ being used in humans and whether or not it is toxic, $\mathrm{SPLA}_{2}$ inhibitors have been used in trials for rheumatoid arthritis and sepsis. There were no noticeable toxicities. Finally, regarding the idea that there could be a single shot approach to addressing anything involving cancer or invasiveness in particular, $\mathrm{SPLA}_{2}$ inhibition is useful as a research tool and may eventually be part of multimodality therapy targeting different pathways that promote malignancy.

Dr Mulligan. Perhaps this is one pathway but maybe not the pathway. 